\title{
ANAESTHETIC EXPERIENCES USING EXTRACORPOREAL CIRCULATION FOR OPEN HEART SURGERY*
}

\author{
E. A. GAIN, M.D. $†$
}

As A RESULT of the rapid advances in cardiac diagnosis in recent years, most centres have established diagnostic cardiovascular units. These units have ciagnosed a large number of remedial congenital lesions and consequently trained cardiovascular surgeons have been attracted to these centres. Initially, they operated only on those lesions which could be remedied without stopping or opening the heart, and which did not require a bloodless field. Most of these procedures were blind procedures and the result often left much to be desired. The demonstration of the feasibility of operating in a bloodless field using hypothermia was a major advance. Hypothermia, however, carries its own hazards; the main drawbacks were the severe time restriction placed on the surgeon and, when operating upon ventricular lesions, the ever-present possibility of ventricular fibrillation.

\section{PUMP OXYGENATOR}

In recent years a few centres have reported an increasing number of successes using the low-flow bubble oxygenator pump for open-heart direct-vision surgery $(1,2)$. Many modifications of this pump oxygenator have been developed, but mostly in the oxygenator, and these so-called low-flow systems are now in use in many centres. This indicates that anaesthetists must shortly become familiar with this technique.

The low-flow pump oxygenator was developed (1) on the basis of the principle of azygos-flow which had proved that Hlows of 8-14 cc. $\mathrm{kg} . / \mathrm{min}$. would keep dogs alive. This principle allowed the development of this simple low-flow machine. With the low-flow there is less coronary bleeding during cardiotomy; therefore, there is less blood loss and less blood is required to prime the pump.

With the original flow rates of $35-40 \mathrm{cc} . \mathrm{kg} . / \mathrm{min}$. in humans there was little evidence of cardiac hyper-irritability. Most workers are now using higher flows ranging from $60-100 \mathrm{cc} . \mathrm{kg}$./min. The newer pumps will delıver up to 3 litres/ min. as compared to a previous 2 litre/min.

This bubble oxygenator provides a normal oxygen saturation, Since it is an open system, the blood leaving the pump has lost a great deal of its $\mathrm{CO}_{2}$ and has a $P \mathrm{CO}_{2}$ of $20-30 \mathrm{~mm}$. $\mathrm{Hg}$ because the $\mathrm{CO}_{2}$ is blown off by the oxygen stream in the oxygenator. Some believe that this should be prevented and so use a $\mathrm{CO}_{2}-\mathrm{O}_{2}$ mixture in the oxygenator. We prefer the respiratory alkalosis which results. We have not encountered any of the deleterious effects which Mendelsohn (2) attributes to carbon dioxide washout.

'Presented at the Anuual Meeting of the Canadran Anaesthetssts' Society at Saskatoon, June 25, 1957.

†Department of Anaesthesiology, University of Alberta and University Hospital, Edmonton 
During the perfusion the mean brachial artery pressure is about $50-60 \mathrm{~mm}$. Hg. There is occasionally a rise in venous pressure which is usually the result of mechanical obstruction from the use of caval catheters which are too small. Some (2) prefer to give vasopressors to raise the arterial pressure during the perfusion. We have not attempted this With the flows now used there appears to be adequate cerebral perfusion as shown by the lack of any change in the postoperative electroencephalographic pattern or in the postoperative clinical condition of the patient. This pump oxygenator is not the ideal desired as the blood flows and arterial pressures are far below normal, and considerable trauma to the blood occurs, this results in considerable metabolic change.

\section{ANAEsthesta}

The anaesthetist who is familiar with the anaesthetic problems of today's routine cardiac surgery will not find any particular anaesthetic problem with these cases. The same principles must be adhered to: exceedingly light levels of anaesthesia, perfect controlled ventilation (which is often difficult to achieve because of a large heart, bilateral pneumothorax, and frequent surgical retraction of the lungs); and adequate but never excessive blood replacement. This latter is essential and is one of the most trying problems

Anaesthesia has been induced by thiopentone with succinylcholne, or cyclopropane oxygen with succinylcholine, followed by endotracheal intubation and controlled respiration using a circle absorber with high gas flows It has been maintained either with nitrous oxide-oxygen 60:40 with intermittent succinylcholine, or with ether-oxygen analgesia The latter is preferred by many of us. We prefer to avoid intravenous agents as much as is possible in these patients. The anaesthetic agent chosen is not of great importance as long as it is used correctly. The only respiratory complications which occurred were in four patients anaesthetized with nitrous oxide-oxygen and succinylcholine. Two of these patients had exceedingly high right ventricular pressures and this type of case is prone to develop respiratory complications $(1,2)$. We cannot agree with Mendelsohn's (2) opinion that ether causes a greater incidence of respiratory complications, as yet we have not encountered any with ether.

During by-pass gaseous agents are eliminated and the patient awakens, if the patient does not awaken then, we are concerned. It is often necessary to give a very small dose of barbiturate or meperidine and succinylcholine to control the patient during by-pass. We have not attempted to anaesthetize the oxygenator $(2,4)$ and as this is such an open system we doubt if it would be effective unless very high concentrations of anaesthetic gases were used. This we consider to be too dangerous when this open system and a pump which is not explosion proof are used.

This problem of awakening rarely occurred when flows of $35-40 \mathrm{cc} . \mathrm{kg} . / \mathrm{min}$. were used as the cerebral hypoxia was usually sufficient anaesthesia. Now, with flows of $60 \mathrm{cc} . \mathrm{kg} / \mathrm{min}$., the patient invariably awakens and commences to move. 
Only minute doses of barbiturate or meperidine are required in most instances in spite of the high dilution of the drug by the patient's blood plus the blood in the pump.

The electroencephalograph is used constantly and is believed to be one of our most valuable monitors $(3,4)$. It tells us the depth of anaesthesia, the state of the cerebral circulation and the operating efficiency of the extracorporeal circulation If there is deep anaesthesia, obstruction to the arterial or venous flows, or a shunt as with an unrecognized patent ductus, the electroencephalograph will immedrately give a gross easily recognized warning. An occasional complication, which the anaesthetist must watch for, is cerebral congestion; it is usually the result of mechanical obstruction and is readily detected if the electroencephalographic record and the congested appearance of the head are noted. Other monitors which help the anaesthetist are the electrocardiograph and the intraarterial and intravenous pressure tracings. The latter are of considerable help as an aid in regulatıng blood replacement.

Durnng the extracorporeal circulation no anaesthetic gases other than oxygen are given. The lungs are mauntained partially inflated to prevent complete collapse, but respiratory exchange is not necessary durng this period.

Blood loss is often considerable when the heart is opened. No serious attempt is made by the anaesthetist to replace this loss, which can be done much more efficiently by the pump. Before by-pass is commenced blood loss is replaced as accurately as is possible by the anaesthetist, using citrated blood. When by-pass and cardiotomy and repair are commenced, two suction set-ups, one for the heart and one for the chest cavity, are used, all blood lost is suctioned and measured in sterile calibrated containers. The blood from the heart suction is returned to a special pump and can be recirculated if necessary. The fall in blood level of the pump helix approximates closely the blood lost through the suctions. This is replaced by adding blood to the pump and all replacement is carried out by the pump until the catheters are removed when the anaesthetist again assumes this duty.

The patient is weighed before and after surgery as a check on blood replacement, and recently radioactive chromium estumations are being done when possible It is believed that, if heart action is good, the intra-arterial and intravenous pressures, plus the anaesthetist's estimate of the patient's condition, are the best indicators of the adequacy of blood volume regardless of measured loss and replacement.

The use of cardiac arrest greatly reduces the blood loss since there is no coronary flow. Cardiac arrest produced by acetylcholine was used routinely for a few patients, but the surgical team did not feel that the advantages outweighed the possible risks, especially during long perfusions; the surgeon's difficulties created by a moving heart have decreased with experience and cardrac arrest is seldom used now. It is not known how long the arrested heart without coronary circulation can survive without damage to myocardium and conductive tissue. At present cardiac arrest is only produced when the surgeon believes that it is necessary for technical reasons 


\section{Surgical Procedure}

Briefly the surgical procedure is as follows. The inferior and superior venae cavae are catheterized through the right atrial appendage for the pump inflow, and the femoral artery is catheterized for the pump outflow. The patient is previously heparinized with heparin $1.5 \mathrm{mg} . / \mathrm{kg}$. The base of the aorta is cleared and an exploration for a patent ductus is made routinely.

During this period the pump is being primed with heparinized blood which is collected the same morning and the pump is calibrated for the desired output. Following exploration for the ductus the pump is started and run for about thirty seconds before the venae cavae are occluded; then continued for another one or two minutes after total venous occlusion. If the electroencephalograph is satisfactory, the pupils remain constricted and there is no evidence of venous congestion, the aorta is clamped and acetylcholine $10 \mathrm{mg} . / \mathrm{kg}$. is injected into the brise of the aorta to perfuse the coronaries (this only if cardiac arrest is desired), when cardiac arrest occurs rapidly.

Cardiotomy is then performed and the repair carried out. Following repair and closure of the cardiotomy the clamps are removed from the aorta and venae cavae and perfusion of the heart occurs, if cardiac arrest has been used, the acetylcholine effect disappears, and a normal beat is resumed in a matter of $1-2$ minutes. The pumps are then stopped and the andesthetist surveys the patient's clinical condition and estimates the need of further transfusion. If he believes that further blood replacement is required, he orders what volume he wishes to be given from the pump. This is done by turning on the outtlow side of the pump only and may be repeated several times until the anaesthetist is satisfied. With the heart and the intra-arterial and intravenous pressures under constant observation, overload is easily detected and if it should occur the excess blood can be removed by utilizing the venous side of the pump; we prefer to be slightly deficient in blood replacement.

When everybody concerned is satisfied with the clinical state of the patient the catheters are removed, protamine $1.5 \mathrm{mg} . / \mathrm{kg}$. is given and the closure commences. The anaesthetist changes back to citrated blood and this is used until all evidence of blood loss ceases. This period may last 48 hours as every drop from the chest drains in the postoperative period is accurately measured and usually replaced.

The patient should be awake before leaving the operating room, preferably before the last sutures are inserted. If the patient is not awake then cerebral hypoxia has probably occurred either from poor perfusion or possibly from air embolism. Anaesthetic overdose should not occur with the technique used. One can usually predict from the EEG. during and after the perfusion whether there will or will not be a delay in recovery. In three patients return of consciousness was delayed for 30-60 minutes. Early in this series one patient suffered severe cerebral hypoxia and did not awaken for 48 hours, then made a rapid and apparently uncomplicated recovery; air embolism was suspected as the EEG. pattern deteriorated after the aortic clamp was released.

During and after operation arterial blood samples are taken frequently for 
study. The physiological changes which occur have been presented in detai by others $(1,2,3)$ with much larger series. Here, it suffices so say that biochemica changes are infrequent until after the termination of the by-pass. At this time significant metabolic acidosis often begins to manifest itself, especially with very long perfusions and in cyanotic patients, but rarely after short runs of ten to fifteen minutes. The acidosis is the result of an increase in lactic acid with a fall in bicarbonate, most likely the result of the low tissue perfusion. If severe this acidosis is treated with intravenous bicarbonate. If circulation and respiration are adequate after by-pass, the acidosis will correct itself in most patients. Hypokalemia usually occurs in acyanotic patients, but a hyperkalemia may occur in those who are cyanotic. The potassium disturbances are rarely severe enough to require treatment. There is a marked rise in blood sugar levels, but other biochemical changes have not been significant.

Haemolysis occurs in every case. The amount is usually directly proportional to the flow and duration of the pump run. As yet no ill effects have been noted from haemolysis; levels under $200 \mathrm{mg}$ per cent appear to be innocuous (1). Very little is known of other changes in the blood factors other than that severe platelet destruction occurs. Bleeding and clotting times have all been normal after protamine. Some writers have emphasized the difficulty with post-operative bleeding $(1,4)$, It occurred in two patients in this group, one required operative correction. One patient developed an uncontrollable haemorrhagic diathesis during surgery; citrate intoxication was suspected.

Arrhythmias after repair of the defect have been a frequent problem. One patient with supraventricular tachycardia was effectively treated with methoxamine. Four patients (one with Eisenmenger's Complex, two with Tetralogy of Fallot, one with an atrial-septal defect) developed an A.V. conduction defect. All except the one with the atrial-septal defect died suddenly, 9, 24, and 2 hours postoperatively. All had apparently recovered and were maintaining an adequate circulation, when presumably complete block developed. Sudden, unexpected, unexplained death in the first 24 hours is not a rarity. This has been the experience of all workers in this field and it has been suggested that postoperative oedema from the repair interferes with the conductive tissue of the heart causing sudden cardiac standstill. Conduction defects are frequent with some ventricular septal defects and with atrial ostium primum defects. Isopropylarterenol has been used for the treatment of these conduction defects, but with little success in our cases.

There has not been any clinical evidence postoperatively of any damage to vital organs attributable to the pump oxygenator. None of the deaths could be attributed to the pump or anaesthetic agent or method of administration.

Table I shows the perfusion and anaesthetic times and some of the more important biochemical changes. More extensive details of this nature are to be found in Buckley's (1), Mendelsohn's (2) and Matthew's (3) papers.

The following tables show that a wide variety of lesions have been treated. No attempt was made to select the patients; all were treated as they were brought to the cardiovascular unit. Many patients had multiple cardiac defects and all 


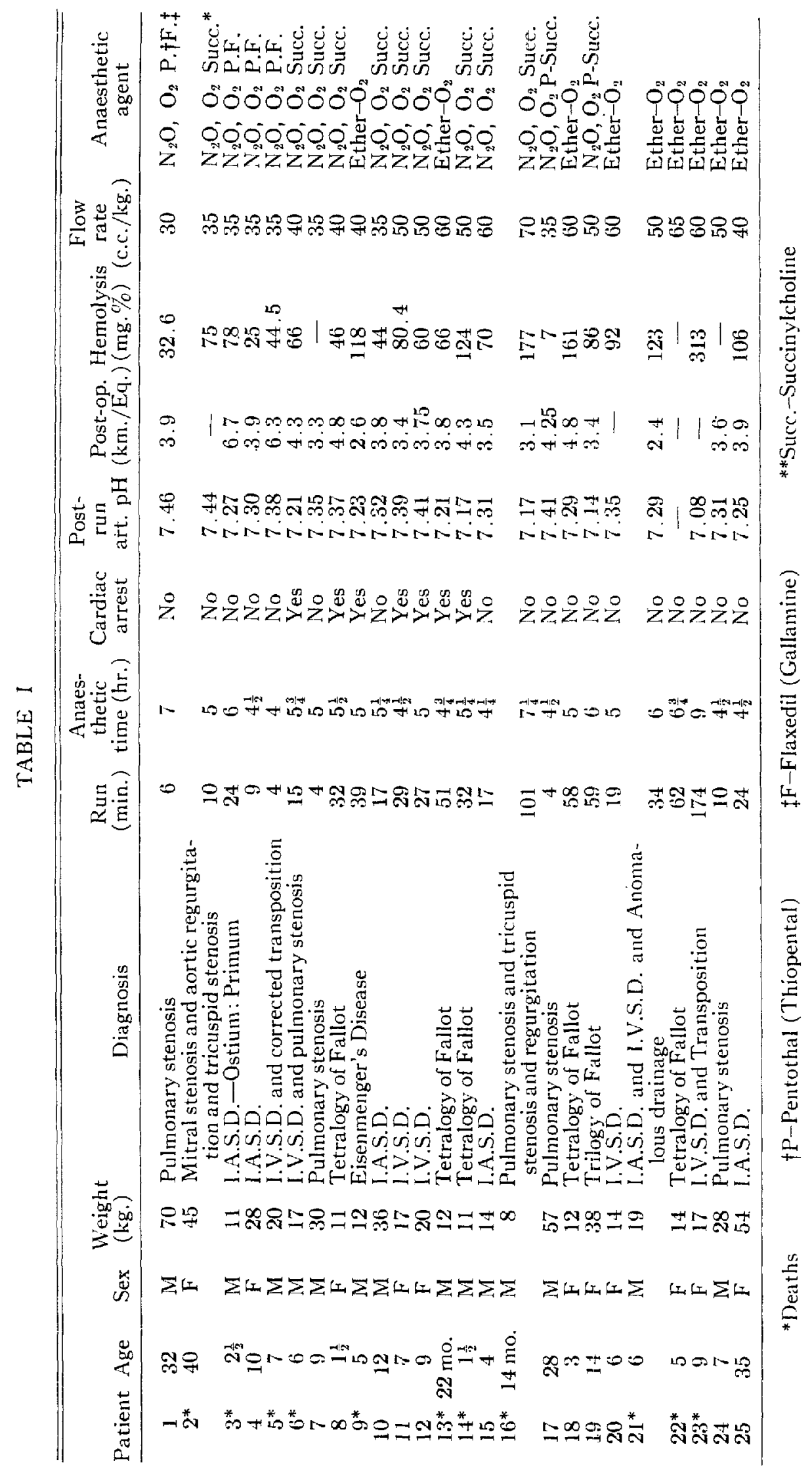


defects were repaired except one (case \#5). Four patients had undergone previous palliative cardiac surgery with poor results; none survived this procedure. The over-all mortality was 44 per cent. For twelve patients with single defects the mortality was 8.3 per cent.

The fatalities are listed below.

\section{Lesion}

Interventricular septal defect

Interatrial septal defects

Ostium primum

Ostium secundum

Pulmonary stenosis

Trilogy of Fallot

Tetralogy of Fallot

Interventricular septal defect with pulmonary stenosis

Pulmonary stenosis with tricuspid stenosis and regurgitation

Interatrial septal defect with interventricular septal defect and anomalous dranage

Eisenmenger's complex

Trans zortation and interventricular septal defect

Mitra stenosis with regurgitation and tricuspid stenosis and aortic regurgitation

Mortality-44 per cent

"Indicates previous cardiac surgery.
Number of each

3

40

$4-0$

$1 \quad 0$

5

1

1

1

$2\left(1^{*}\right)$

$\frac{1}{25}$

It will be seen that most of these were patients with multiple lesions and those patients who had undergone prevous unsuccessful surgery using other methods.

We believe that this method for open-heart surgery will soon become as commonplace as pulmonary and neurosurgery, and it is necessary that anaesthetists familiarize themselves with the physiology of these cardiac lesions, with the surgical procedures involved, with the anaesthetic problems which occur, and with the constant changes and advances in this branch of surgery.

Patient

Lesion

2 Mitral regurgitation and stenosis

3 Atrial septal defect, ostium primum type

5 Common ventricle (large I.V S D ) and corrected transposition

6 Interventricular septal defect and pulmonary stenósis

9 Eisenmenger's Complex

13 Tetralogy of Fallot

\section{Comment}

Previous commissurotomy. Cardiac cripple Severe haemorrhage, died in operating room. Autopsy revealed aortic regurgitation and tricuspid stenosis also present

Died four hours postoperatively. Severe acidosis, hypotension, bypovolemia Autopsy negative, Bundle of $\mathrm{H}$ is possibly involved in repair

Exploratory cardiotomy only. Died twelve hours postoperatively. Clinical cardiac failure Autopsy negative.

Suspect air embolus. Coma two days Good recovery. Wound disruption eighth day and cor pulmonale developed Cardiac falure during closure Autopsy. incomplete closure of defect.

Post repair conduction defect Sudden death nine hours postoperatively. Autopsy negative

Post repair conduction defect. Sudden death twentyfour hours after operation. Autopsy. sutures pulled out of septal defect Outflow patch incorrectly placed. 
Patient Lesion

14 Tetralogy of Fallot tricuspid stenosis and regurgitation

21 Interatrial septal defect with interventricular septal defect and anomalous drainage

22

Tetralogy of Fallot

Interventricular septal defect and transposition
16 Pulmonary stenosis with

Comment

Post repair conduction defect Sudden death two hours postoperatively. Autopsy negative.

Previous reparr pulmonary stenosis at six months under hypothermia. Died in operating room. Severe haemorrhage during attempted insertion of plastic tricuspl valve. Pulmonary stenosis corrected.

Preoperative hustory of epilepsy. Well for 32 hours postoperatively, then had two seizures and died Autopsy negative, except one suture pulled out of ventricular septal patch

Previous Brock Procedure. Uncontrollable haemorrhage from tears in left lung Died in operating room. Autopsy riegative, good reparr

Previous Pott's procedure, Developed haemorrhagic diathesis before by-pass, suspected citrate intoxication Put on pump and baffle insertion attempted Died in operating room Autopsy negative.

\section{RÉSUMÉ}

Nous avons fait part de notre expérience en anesthésie acquise au cours de 25 cas où l'on a employé la pompe de Lillehe et Dewall, oxygénateur barboteur à faible débit. Au cours de ce travail un des problèmes les plus difficiles à été l'évaluation de pertes sanguines et de leur remplacement pour maintenir l'équilibre de la masse sangune circulànte.

L'auteur est d'avis que d'ici à ce que nous ayons acquis plus d'expérience, il est essentiel que, dans ces cas, nous enrégistrions les pressions veineuse et artérielle de même que l'électroencéphalogramme afin d'être renseignés à tous les instants sur les pertes sanguines et leur remplacement, sur le niveau d'anesthésie et sur l'efficacité de la circulation artificielle.

Comme techniques et agents anesthésıques, nous avons employé les barbituriques intraveineux et les paralysants musculaires avec le protoxide d'azote et l'oxygène ou l'analgésie à l'éther. Nous préférons cette dernière technique. Quand nous le pouvons, nous laissons de coté les barbituriques intraveineux qui diminuent le débit cardiaque et s'éliminent difficilement et lentement. En anesthésie, toutes les méthodes sont bonnes si l'on respecte les principes essentiels: une anesthésie très légère et un contrôle parfait de la ventilation. Dans quelques cas, nous avons provoqué l'arrêt cardiaque avec de l'acetylcholine: cette façon d'agir ne présente pas d'avantages et nous l'employons seulement quand le chirurgien l'exige pour certaines raisons techniques.

Il est apparu fréquemment des troubles de conduction, signature d'un pronostic sombre. Il n'a pas été rare de constater des morts subites durant les 24 premières heures. Selon toute apparence, les organes vitaux n'ont subi aucun dommage ni par l'anesthésie ni par la circulation extracorporelle.

Nous n'avons pas tenté de choisir les cas, nous en avions une grande variété: on trouvera dans les tables, les résultats obtenus et les causes de mort. L'auteur 
a l'impression que cette technique va devenir bientôt d'usage courant dans les centres importants et que les anesthésistes devraient se familiariser avec les problèmes anesthésiques et chirurgicaux que pose cette section de la chirurgie.

\section{REFERENCES .}

1 Buckley, J. Physiological Disturbances during Low-Flow Extracorporeal Circulation. Presented before Western Divisıon, Canadian Anaesthetists' Society (March, 1957)

2 Mendelsohn, David, Jr. Experiences Using the Pump Oxygenalor for Open Cardiac Surgery in Man. Anesthesiology 18. 223 (March, 1957).

3. Matthews, J. Acute Effect of Low-Flow Extracorporeal Circulation on Cerebral Physiology. Anesthesiology 18: 169 (Jan., 1957).

4 PATRICK, R. T Personal communication 